\title{
Pay Piyasalarında Getiri Volatilitesinin Modellenmesi: BİST -100 İçin Klasik ve Bayesci GARCH Yaklaşımları
}

\author{
Muhammet Burak Kılıça
}

\author{
İsmail Çelik ${ }^{\mathrm{b}}$
}

\author{
Murat Kaya ${ }^{\mathrm{c}}$
}

Öz: Yatırım araçlarından beklenen getirinin elde edilmesi kadar yattım risklerinde tahminin doğruluğu da yattrımı karakteristikleri açısından önem taşımaktadır. Finansın en temel ikilemlerinden biri olan risk ve getiri konusunun risk ayağına yoğunlaşan çalıșmalarda model artkklarının sahip olduğu kalın kuyruk özelliği endeks getirileri için uygun risk tahmin modelinin elde edilmesini zorlaştırmaktadır. Şubat 2007-Şubat 2017 aralığındaki günlük Borsa istanbul (BiST100) endeks verilerinin kullanıldığı bu çalışmada Student-t artılarıyla klasik ve Bayesci GARCH $(1,1)$ modellerinin, pay senedi getiri volatilitesi üzerindeki etkilerinin karşılaştırılması amaçlanmaktadır. Araştırma sonucunda pay senedi getiri volatiliteleri için tahmin edilen klasik ve Bayesci GARCH(1,1) - Student-t model sonuçları arasında hem şokların volatilite üzerindeki etkisi hem de volatilite kalııılığı açısından çok önemli bir farklıık bulunamamıştır. Bu durum her iki tahmin modelinin birbirinden ayırt edilmediği şeklinde yorumlanabilir. Sonuç olarak klasik ve Bayesci GARCH(1,1) Student- $t$ tahmin modelleri, pay senedi getiri volatilitesinin modellenmesinde, yatrımcılara ve piyasa düzenleyicilerine yatrım riskinin tahmini açııından güvenilir sonuçlar sunmaktadır.

Anahtar Sözcükler: BiST-100, Pay Senedi Getirileri, Volatilite, Student-t Dağııımı, Bayesci Yaklaşımlar

JEL Sınıflandırması: C46, C58 G11, G12

\section{Modeling of Volatility in the Stock Markets Returns: Classic and Bayesian GARCH Approaches for ISE -100}

\begin{abstract}
The accuracy of estimate in the investment risk is important for the potential investors as well as the expected return from the investment characteristics. One of the most fundamental issues on risk and return is to have the heavy tailed behavior of the residuals that makes it difficult to obtain an appropriate risk prediction model for index returns in financial studies. In this study, Istanbul stock exchange (ISE-100) daily index data between February 2007 and February 2017 is analyzed with the classic and Bayesian GARCH $(1,1)$ models and it is aimed to compare the effects of them on return volatility with Student-t residuals. As a result of this study, no significant differences are found between the classical and Bayesian GARCH (1,1)-Student-t models both effects of shock on volatility and volatility persistence for stock return. This can be interpreted as both models not well differentiated from each other. In conclusion, classical and Bayesian GARCH (1,1)-Student-t estimation methods provide reliable results both in modeling volatility of returns and in estimating investment risk for investors and market regulators.
\end{abstract}

Keywords: ISE-100, Stock Returns; Volatility, Student-t Distribution, Bayesian Approaches

JEL Classification: C46, C58 G11, G12

${ }^{a}$ Asst. Prof., PhD., Mehmet Akif Ersoy University, Faculty of Economics and Administrative Sciences, Department of Business Administration, Burdur, Turkiye, mburak@mehmetakif.edu.tr

${ }^{b}$ Asst. Prof., PhD., Mehmet Akif Ersoy University, Faculty of Economics and Administrative Sciences, Department of Banking and Finance, Burdur, Turkiye, ismailcelik@mehmetakif.edu.tr

Asst. Prof., PhD., Mehmet Akif Ersoy University, Faculty of Economics and Administrative Sciences, Department of Banking and Finance, Burdur, Turkiye, mkaya@mehmetakif.edu.tr 


\section{Giriş}

Modern portföy teorileri açısından yatırımcılar için beklenen getirinin elde edilmesinde ortaya çıkacak risklerin daha isabetli bir şekilde tahmin edilmesi, geleceğe ilişkin risklerin yönetimi açısından oldukça önem kazanmaktadır. Finansın en temel portföy teorileri arasında sayılan Sharpe-Linter Finansal Varlıkları Fiyatlama Modeli gibi ortalama-varyans portföy teorilerinin deneysel testlerinde varlık getirilerinin varyans ve kovaryansı risk ölçümünde kullanılmaktadır (Bollerslev, 1987:542). Pay piyasaları arasındaki entegrasyon seviyesinin özellikle finansal liberalleşme sonrası artan boyutlara ulaşması piyasalarda meydana gelen bilgi şoklarının etkisini artırmakta olup pay senedi getirilerinin dağılımsal özelliklerini etkilemektedir. Dağılımsal özellikler, Black-Scholes opsiyon fiyatlama modeli ve Etkin Piyasalar Hipotezinin test edilmesi gibi modellerde önemli rol oynamaktadır (Bollerslev, 1987:542).

Pay senedi getiri volatilitesi, pay senedi fiyatlarındaki değişkenliği ifade eder. Yatırımcılar, analistler, aracı kurumlar ve politika yapıcıların getiri volatilitesini önemsemelerinin nedeni, bir risk göstergesi olmasının yanında, aynı zamanda piyasanın tamamından veya firmalardan kaynaklanan önemli bilgilere eşlik etmeyen pay senedi fiyat dalgalanmalarından endişelenmeleridir. (Karolyi, 2001:1). Aşırı volatilitenin varlığı pay senedi getirilerinin yüksek tutarlı kazançlara/kayıplara yol açabileceğinden, piyasaya ya da pay senetlerine karşı güvensizlik algısı oluşturmaktadır.

Geleneksel zaman serisi ve ekonometrik modeller sabit varyans varsayımına göre çalıştııımasına rağmen, volatilite analizlerinde yaygın şekilde kullanılan ve Engle (1982) tarafindan ortaya konan ARCH modeli koşulsuz ve koşullu varyans arasındaki farkı, zaman içerisindeki değişime izin veren geçmiş hataların bir fonksiyonu olarak açıklamaktadır (Bollerslev, 1986:307). ARCH modelinin koşullu hata dağılımı normal dağılım özelliği gösterirken, koşullu varyans geçmiş hata karelerinin doğrusal bir fonksiyonudur. Finansal piyasalarda, pay senedi dalgalanmaları, normal dağılım varsayımı yerine, riskin daha doğru belirlenmesi için student-t, genelleştirilmiş hata dağııımı, çarpık normal dağılım gibi, basık olan dağıımların kullanımlarına neden olmaktadır. Bu dağılımların kullanılmasının önemi ilk olarak Bollersev (1987)'de GARCH(1,1)-Studentt modeliyle ortaya çıkmış olup, normal dağılım varsayımı yerine, hata terimi için daha esnek bir parametrik dağılımın kullanılması finansal zaman serilerinde risk tahmininde daha güvenilir sonuçlar vermiştir (Hsieh, 1989; Baillie and Bollerslev, 1989, 1991; Engle, Ito ve Liu 1990; Engle and Gau, 1997; Johnston and Scott, 2000, Hoogerheide, Ardia ve Corre, 2012). Bu bağlamda çalışmanın amacı, normallik varsayımı yerine hata terimlerinin Student-t dağılımına sahip olduğu varsayımı göz önüne alınarak BiST-100 için klasik ve Bayesci GARCH(1,1) modellerini volatilite açısından karşılaştırmaktır.

Diğer taraftan; literatürdeki diğer çalışmalara bakıldığında, Bayesci yöntemlerin son yıllarda çok kullanıldığı görülmektedir. Örneğin, Iqbal (2016), 2008 yılı küresel finansal krizinin öncesinde ve sonrasında, Karachi Borsası'nın Riske Maruz Değerinin (VaR) tahmini ve öngörüsüne ilişkin çalışmasında, Bayesci yöntemi kullanarak; makul VaR oranları ve daha düşük kayıplar sağlayan Bayesci yöntemin VaR'nin tahmini için güvenle kullanılabileceği sonucuna ulaşmıştr. Ho, Lee ve Marsden (2011) ve Amiri (2010), farklı dönemlerde $A B D$ ve Tahran pay senedi fiyatlarındaki volatiliteyi modellemeyi amaçladıkları çalışmalarında; Bayesci modeller ile yapılan tahminlerin, diğer volatilite modelleri ile yapılan tahminlere göre daha başarılı sonuçlar verdiğini tespit etmişlerdir. Hoogerheide vd. (2012), uzun dönemli olarak S\&P500 ve Nikkei 225 endeks getirilerinin GARCH modelleri kullanılarak En çok olabilirlik (EO) tahmini ve Bayes tahmini arasında bir karşılaştırma yaptıkları çalışmalarında, yöntemler arasında anlamlı bir fark bulunmamıştı. Güriş ve Saçıldı (2011), 04.01.1995-18.06.2010 arası verileri kullanarak iMKB'de işlem gören pay senedi getirileri için, normal artklar ile klasik GARCH $(1,1)$ ve Bayesci GARCH(1,1)-student-t modellerini karşılaştırmışlardır. Student-t artklarına sahip Bayesci GARCH model tahminlerinin iMKB-100 getiri endeksi için daha iyi yakınsama sağladığını tespit etmişlerdir.

Türkiye finans piyasası açısından BIST-100 ile ilgili yapılan çalışmalara bakıldığında ise volatilite kalıcılığının tahmini için bir çok model önerilmiştir. Bu çalışmalardan bazıları; Yıldız (2016), Borsa İstanbul (BIST)'a kayıtlı seçilmiş alt sektörler arasında yer alan hizmet, mali ve sınai endeks getiri serilerine ait 05 Ocak 2000 - 09 Aralık 2015 tarih aralığındaki volatiliteleri tahmin ettiği çalışmasında, mali ve sınai endekslere ait volatilite tahminlerinde en uygun modelin $\operatorname{TGARCH}(1,1)$, hizmet endeksine ait volatilite tahmininde ise en 
uygun modelin ise CGARCH $(1,1)$ olduğu sonucuna ulaşılmıştr. Göktaş ve Hepsağ (2016), BIST-100 endeksinin volatil davranışlarını simetrik ve asimetrik stokastik volatilite modelleri ile analiz ettikleri çalışmalarında, 02.01.2009-16.05.2014 arası günlük verileri kullanmışlar ve gerek klasik stokastik volatilite modeline ait tahmin sonuçlarına, gerekse dinamik kaldıraç etkili stokastik volatilite modeli sonuçlarına göre; BIST-100 endeksinin yoğun şekilde bir volatilite kalıcılığına sahip olduğu ve BiST'te, volatilite kümelenmelerinin oluştuğu, volatilite değişkenliğinin düşük seviyede ve volatilitenin öngörülebilir bir piyasa olduğu sonucuna ulaşmışlardır. Kayahan, Kandemir, Baykut ve Memiş (2015), 30.06.2008- 30.06.2009 arası verileri kullanarak IMKB 30 endeksi ve USD/TRL kurundaki volatiliteyi tahmin ettikleri çalışmalarında; GARCH $(1,1)$ modeli ile diğer GARCH modelleri ve EWMA modeli arasında istatistiksel olarak anlamlı bir fark bulunmadığı sonucuna ulaşmakla birlikte, tarihsel volatilite ve $\operatorname{GARCH}(1,1)$ modeline dayalı modeller arasında önemli farklılıklar bulunmuştur. Eryılmaz (2015), 1997 birinci çeyrek ve 2015 üçüncü çeyrek arası BiST 100 için pay senedi getiri volatilitesini incelemek amacıyla, ARCH, GARCH, EGARCH ve TARCH modellerini kullandığı çalışmasında; volatilite tahmini için en uygun modelin $\operatorname{EGARCH}(1,1)$ olduğunu tespit etmiştir. Ayrıca çalışmada; kaldıraç etkisinin BIST-100 için önemli olduğu, piyasaları olumsuz etkileyen haberlerde oynaklığın arttı̆ı ve oynaklığın süreklilik taşıdığı sonuçlarına ulaşılmıştır. Altuntaş ve Çolak (2015), farklı dönemlerde BisT 100 endeksindeki volatiliteyi araştırdıkları çalışmalarında; kriz dönemlerini içeren 03.01.1994 - 28.12.2001 tarihleri arası için simetrik koşullu değişen varyans modellerinin, kriz dönemi sonrasını ifade eden 02.01.2002-31.12.2009 tarihleri arası için ise, hem simetrik hem de asimetrik koşullu varyans modellerinin uygun olduğu sonucuna ulaşmışlardır. Karabacak, Meçik ve Genç (2014), BisT 100 endeks getirisi ve altın getirisi volatilitesinin modellenmesi için en uygun koşullu değişen varyans modellerini belirlemeyi amaçladıkları çalışmalarında, BIST 100 endeks getirisi için 3 Ocak 2003- 11 Eylül 2013 tarihleri arası, altın getirisi için ise 3 Ocak 2005- 10 Eylül 2013 tarihleri arası verileri kullanmışlar ve BIST 100 endeks volatilitesi için en uygun modelin TARCH $(1,1)$, altın getirisi volatilitesinin ölçülmesi için ise en uygun modelin $\operatorname{GARCH}(1,1)$ modeli olduğu sonucuna ulaşmışlardır. Gökbulut ve Pekkaya (2014), Türkiye finansal piyasalarındaki BiST100, faiz ve döviz kuru getiri volatilitesi için, 2002-2014 yılları arası yaptkkları çalışmalarında; CGACRH ve TGARCH modellerinin en uygun modeller olduğunu ve tüm getiri serilerinde, asimetri, volatilite kümelenmesi, kalın kuyruk ve uzun hafizanın varlı̆ı̆ı tespit etmişlerdir. Atakan (2009), ARCH ve GARCH metotları kullanarak İstanbul Menkul Kıymetler Borsası'nda volatiliteyi modellediği çalışmasında, araştıılan tüm model tahmin sonuçları içerisinde Akaike Bilgi Kriteri değerlendirme sonucuna göre, $\operatorname{GARCH}(1,1)$ modelinin IMKB- 100 Endeksi günlük getiri serisindeki değişkenliği modellemede kullanılabilecek en uygun model olduğu sonucuna ulaşılmıştır.

Bu çalışmada ise, finansal piyasalarda getiri volatilitesinin modellenmesinde çoğunlukla normal dağılmayan artklardan dolayı artkların student-t dağıımına sahip olduğu $\mathrm{GARCH}(1,1)$ student-t model parametreleri EO ve Bayesci yöntemle tahmin edilerek karşılaştırılmıştır. Çalışmanın ikinci bölümünde araştrrmada kullanılan yöntemler, üçüncü bölümünde ise elde edilen bulgular sunulmuştur. Çalışmadan elde edilen sonuçların yorumlanmasına sonuç kısmında yer verilmiştir.

\section{GARCH Modellerinin Klasik Ve Bayesci Tahminleri}

\subsection{GARCH Modellerinin Klasik Tahmini}

Bollerslev (1986) tarafindan ortaya konulan GARCH(p,q)-Normal formülasyonu (1) numaralı denklem ile ifade edilmiştir.

$$
\begin{aligned}
& \varepsilon_{t} \mid \phi_{t-1} \square N\left(0, h_{t}\right), \\
& h_{t}=\alpha_{0}+\sum_{i=1}^{q} \alpha_{i} \varepsilon_{t-i}^{2}+\sum_{i=1}^{p} \beta_{i} h_{t-i}
\end{aligned}
$$

Burada $p \geq 0, q>0, \quad \alpha_{0}>0, \quad \alpha_{i} \geq 0, \quad i=1, \ldots q, \beta_{i} \geq 0, i=1, \ldots p$. ve $\phi_{t-1}$ piyasadaki tanından önceki enformasyonu gösterir. Denklemde $\alpha_{0}$ katsayısı sabit terimini, $\alpha_{i}$ şokların volatilite üzerindeki etkisini, $\alpha_{i}+\beta_{i}$ ise şokların volatilite üzerindeki etkisinin hangi hızda azalacağını ifade etmektedir. Bu toplam 
1'e yaklaştıkça kalıcılık (ısrarcılık) artacaktır. Durağanlık koşulu için de toplam 1'den küçük olmalıdır. $\operatorname{GARCH}(p, q)$ modellerinden en çok kullanılan $\operatorname{GARCH}(1,1)$-Normal modeli ise (2) numaralı denklem ile ifade edilir.

$$
\begin{aligned}
& \varepsilon_{t} \mid \phi_{t-1} \square N\left(0, h_{t}\right), \\
& h_{t}=\alpha_{0}+\alpha_{1} \varepsilon_{t-1}^{2}+\beta_{1} h_{t-1}
\end{aligned}
$$

$\alpha_{0}>0, \alpha_{1} \geq 0$ ve $\beta_{1} \geq 0$ ile ifade edilir. Özellikle normal artılar varsayımı altında, çoğu finansal varlığın getirisinin koşulsuz dağılımının, modelin varsaydığı normal dağılıma nazaran daha kalın kuyruk yapısına sahip olması nedeniyle uygulamaların reddedilmesine sebep olmaktadır. Aşırı basıklık çoğu zaman student-t dağılımına uyum göstermektedir. Student-t dağılımı, finansal zaman serilerindeki aşırı basıklık özelliğini normal dağııımdan daha iyi yansıtmaktadır. Bollerslev (1987) tarafindan ortaya konan student-t dağılıma sahip GARCH(1,1)- student-t modeli (3) numaralı denklem ile formüle edilmiştir.

$$
\begin{aligned}
& y_{t}=E\left(y_{t} \mid \phi_{t-1}\right)+\varepsilon_{t}=y_{t \mid t-1}+\varepsilon_{t} \\
& \varepsilon_{t} \mid \phi_{t-1} \square f_{v}\left(\varepsilon_{t} \mid \phi_{t-1}\right) \\
& h_{t}=\alpha_{0}+\alpha_{1} y_{t-1}^{2}+\beta h_{t-1}
\end{aligned}
$$

$f_{v}$ hata terimlerinin Student-t dağıldığını ifade eder.

GARCH(1,1)- normal ve GARCH(1,1)- student-t modellerinin parametre tahminleri için genel olarak EO yaklaşımı tercih edilir. Parametre tahmininde EO'nin kullanılmasının sebebi, altında yatan sezgisel prensip ve uygulama kolaylığı olmasına rağmen, EO tahmini yönteminde, eşitsizlik kısıtlamalarını içeren sayısal optimizasyonlar nedeniyle uygulamada bazı zorluklar ortaya çıkardığı bilinmektedir (Hoogerheide vd., 2012; 322). Bu nedenle, parametre tahminlerindeki çeşitli optimizasyon zorlukları farklı tahmin yöntemlerinin düşünülmesine ve geliştirilmesine neden olmuştur. Çalışmanın bir sonraki kısmında Bayesci GARCH(1,1)student-t modeline yer verilecektir.

\subsection{Bayesci GARCH $(1,1)$ - Student-t Modeli}

Bayesci paradigma veri ile önsel bilgileri teorik bir çerçeve ile birleştirmesinden dolayı, model parametre tahminleri açısından daha güvenilir bir yaklaşım sunar. Böylelikle, geçmişteki bir parametre hakkında elde edilen önsel bilgileri, gelecekteki analizler için, bir önsel dağılım olarak kullanılmasına olanak sağlar. Önsel dağılımlar, objektif, belirsiz veya sübjektif olabilirler ve model çıkarsamaları, Bayes teoreminden elde edilir. Son yıllarda, finansal piyasalarda, Bayesci tahminler, EO yöntemi ile elde edilen tahminlerle karşılaştırıldığında daha güvenilir sonuçlar sunmuştur (Iqbal, 2016; 453). Finansal piyasa açısından, Bayesci tahminlerin küçük örneklemle yapılan analizlerinde EO tahmininden daha başarılı sonuçlar verdiği de görülmüştür (Nakatsuma and Tsurimi, 1996;13).

GARCH (1,1) - student-t modeli, veri arttrma metodu (data augmentation) (Geweke, 1993) ile aşağıdaki (4) numaralı denklem ile ifade edilebilir.

$$
\begin{aligned}
& y_{t}=\varepsilon_{t}\left(\frac{v-2}{v} \omega_{t} h_{t}\right)^{\frac{1}{2}} \quad t=1,2, \ldots, T \\
& \varepsilon_{t} \sim_{i i d} N(0,1) \\
& \omega_{t} \sim_{i i d} I G\left(\frac{v}{2}, \frac{v}{2}\right) \\
& h_{t}=\alpha_{0}+\alpha_{1} \varepsilon_{t-1}^{2}+\beta h_{t-1}
\end{aligned}
$$


$\alpha_{0}>0, \alpha_{1} \geq 0, \beta_{1} \geq 0$ ve $N(0,1)$ standart normal dağılım, $I G\left(\frac{v}{2}, \frac{v}{2}\right)$ ise ters Gamma dağıımını ifade eder. Burada student-t dağılımın serbestlik derecesi $v$ parametresi koşullu varyansın sınırlı ve GARCH model parametrelerinin, $\alpha_{0}, \alpha_{1}$ ve $\beta$ pozitif tanımlı olma kısıtlarını garanti etmiş olur. EO fonksiyonu yazmak için, $y=\left(y_{1}, y_{2}, \ldots, y_{T}\right)^{\prime}, \omega=\left(\omega_{1}, \omega_{2}, \ldots, \omega_{T}\right)^{\prime}$, ve $\alpha=\left(\alpha_{0}, \alpha_{1}\right)^{\prime}$ vektörleri tanımlanır ve model parametre vektörü $\psi=(\alpha, \beta, v)$ olarak tanımlanır. Bu durumda $T \times T$ köşegen matrisi:

$\sum=\sum(\psi, \omega)=\operatorname{diag}\left(\left\{\omega_{t} v-2 / v h_{t}(\alpha, \beta)\right\}_{t=1}^{T}\right.$ ile ifade edilir. EO fonksiyonu ise (5) numaralı denklem ile ifade edilir.

$$
L(\psi, \omega \mid y)=\operatorname{det}(\Sigma)^{\frac{1}{2}} \exp \left(-\frac{1}{2} y^{\prime} \Sigma^{-1} y\right)
$$

Bayesci yaklaşım, model parametrelerini karakterize eden bir $p(\psi, \omega)$ önsel dağılımını düşünür. Bu önsel dağılımlar araştırmacının bilgisine bağlı olarak daha az veya daha çok bilgi içerebilir. Burada önsel dağılımlar ile EO fonksiyonu kullanılarak model parametrelerinin sonsal dağılımını $p(\psi, \omega \mid y)$ elde etmek için Bayes teoremi:

$$
p(\psi, \omega \mid y)=\frac{L(\psi, \omega \mid y) p(\psi, \omega)}{\int L(\psi, \omega \mid y) p(\psi, \omega) d \psi d \omega}
$$

uygulanır. $\operatorname{GARCH}(1,1)$ - student-t modelinin parametreleri $\alpha, \beta$ için önsel dağılımlar;

$$
\begin{aligned}
& p(\alpha) \propto \varphi_{N_{2}}\left(\mu_{\alpha}, \Sigma_{\alpha}\right) I\left\{\alpha \epsilon R_{+}^{2}\right\} \\
& p(\beta) \propto \varphi_{N_{1}}\left(\mu_{\beta}, \Sigma_{\beta}\right) I\left\{\beta \epsilon R_{+}\right\}
\end{aligned}
$$

Burada $\mu_{(.)}, \Sigma_{(.)}$önsel dağılımların hiperparametresi (hyperparameter)dir. I(.) gösterge fonksiyonudur. $\varphi_{N_{d}}$ ise d boyutlu normal dağılım olarak tanımlanır. Bağımsız özdeş dağılımlı $\omega$ parametre vektörünün koşullu $v^{\prime} e$ göre önsel dağıımı (6) numaralı denklem ile ifade edilebilir.

$$
p(\omega \mid v)=\left(\frac{v}{2}\right)^{\frac{T_{v}}{2}}\left[\Gamma\left(\frac{v}{2}\right)\right]^{-T}\left(\prod_{t=1}^{T} \omega_{t}\right)^{-\frac{v}{2}-1} \times \exp \left[-\frac{1}{2} \sum_{t=1}^{T} \frac{v}{\omega_{t}}\right] .
$$

Student-t dağılımının serbestlik derecesi olan $v^{\prime}$ nin önsel dağılımının seçimi için Deschamps (2006) tarafindan önerilen üstel dağılım $\lambda>0$ ve $\delta \geq 2$, (7) numaralı denklemdeki gibi kullanılır.

$$
p(v)=\lambda \exp [-\lambda(v-\delta)] I\{v>\delta\}
$$

Bu seçimin önemli bir avantajı $\lambda$ 'nın çok büyük değerleri için $\delta^{\prime}$ 'da çok büyük seçildiği durumlarda, artkkların normal dağıldı̆̆ı varsayılır. Diğer durumlarda $\lambda^{\prime}$ nın küçük $\delta^{\prime}$ da küçük seçildiğinde artıkların studentt dağıldığı kabul edilir. Son olarak birleşik önsel dağılımlar parametreler arasında bağımsızlık koşulu altında

$$
p(\psi, \omega)=p(\alpha) p(\beta) p(\omega \mid v) p(v)
$$

(8) numaralı denklemdeki şeklinde yazılır. GARCH(1,1) modelinin varyans denklemi için birleşik sonsal dağılımların ve tam koşullu dağıımların kapalı formları mevcut olmadığından, sonsal dağılıma $p(\psi, \omega \mid y)$ yaklaşmak için Markov Zinciri Monte Carlo (MCMC) benzetim yöntemlerine ihtiyaç vardır. illk olarak MCMC örnekleme Metropolis, Rosenbluth, Rosenbluth, Teller ve Teller (1953)'de ortaya konmuş olup, Hastings (1970) tarafindan da genelleştirilmiştir. Örnekleme yöntemi, parametre uzayında gerçekleşen $\left(\psi^{[0]}, \omega^{[0]}\right), \quad\left(\psi^{[1]}, \omega^{[1]}\right), \ldots,\left(\psi^{[j]}, \omega^{[j]}\right), \ldots$, bir Markov zincirinin inşasına dayanır. Düzenli koşul (regularity condtitions) altında $j$ sonsuza gittiğinde asimptotik sonuçlar $\left(\psi^{[j]}, \omega^{[j]}\right) \operatorname{nin} p(\psi, \omega \mid y)$ sonsal dağılıma ait örneklemler olduğunu garanti eder. Dolayısıyla yakma periyodundan sonraki zincirin gerçekleşen değerleri üzerinden birleşik sonsal hakkında çıkarsamalar yapılır (Ardia and Hoogerheide 2010;42). Çalışmada 
kullanılan MCMC metodu Ardia (2008)'deki metotlara dayalı olarak R programı içindeki bayesGARCH (Ardia and Hoogerheide 2010) modülünde yer alan Metropolis Hastings algoritmaları ile çalıştırılmıştır.

\section{Bulgular}

BiST-100 endeksinde işlem gören pay senetlerinin getirilerinde $\operatorname{GARCH}(1,1)$-student-t modelinin klasik ve Bayesci yöntemlerle parametreleri tahmin edilerek getiri serilerinin volatilitesinin tahmini yapılmıştır. Bu çalışmada 02/02/2007-02/02/2017 tarih aralığındaki 10 yıllık günlük veriler kullanılmıştır. Veriler investing.com web sitesinden derlenmiştir. BiST-100 endeksinden logaritmik getirileri hesaplanmış ve $\operatorname{Ln}\left(p_{t} / p_{t-1}\right)$ formülünden faydalanılmıştr. Formülde yer alan $p_{t}, t$ dönemindeki kapanış fiyatlarını $p_{t-1}$ ise $(t-1)$ günündeki kapanış fiyatlarını temsil etmektedir.

Getiri serisine ilişkin zaman serisi grafiği incelendiğinde, BiST-100 getiri serisinin 2008 senesinde oynaklığının yükseldiği, benzer şekilde 2013 senesinde de volatilitenin yüksek olduğu görülmektedir.

Şekil 1: BIST 100 Getiri Endeksinin Zaman Serisi Grafiği

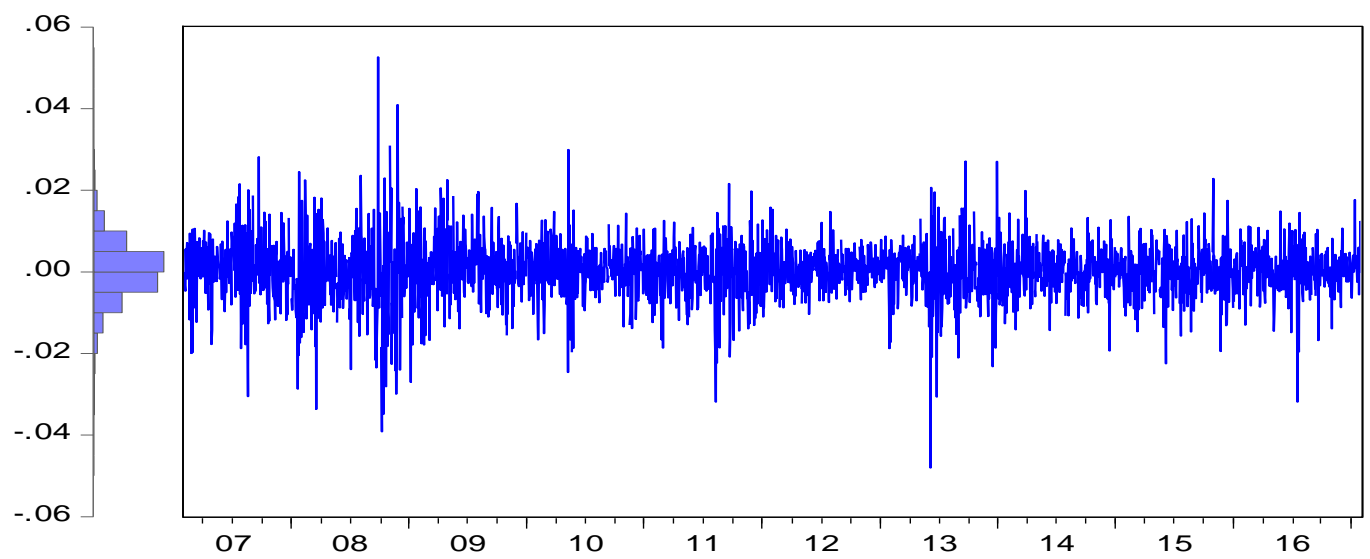

BiST-100 getiri serisine ilişkin betimleyici istatistikler incelendiğinde, çarpıklık ve basıklık katsayıları serinin sola çarpık ve basık karakter sergilediği, JB istatistiğine bakıldığında ise serinin normal dağılım sergilemediği anlaşılmaktadır. Bu sebeple GARCH(1,1)-normal model sonuçları, veri seti normal dağılım sergilemediğinden sonuçların metin içerisinde verilmesine intiyaç duyulmamıştır.

Tablo 1. BIST 100 Getiri Endeksi Tanımlayıcı İstatistikler

\begin{tabular}{|c|c|c|c|c|c|c|c|c|c|c|}
\hline & Ort & Med & Max & Min & SS & Ç & B & JB & Olas. & $\mathbf{N}$ \\
\hline rBiST & ,00012 & ,00032 & ,05267 &,- 04805 & 00739 & -24809 & 7,07073 & 1765,8 & 0000 & 2520 \\
\hline
\end{tabular}
çarpıklık, B: basıklık, JB: Jarque-Bera test istatiği, Olas: JB test istatistiği olasılığı, N ise gözlem sayısını ifade etmektedir.

Tablo 2. BiST-100 Getiri Serisi Birim Kök Test Sonuçları

\begin{tabular}{|c|c|c|c|c|}
\hline & ADF & PP & KPSS & ZA (Yapısal Kırılma Tarihi) \\
\hline Sabitli & $-49,05^{*}$ & $-49,06^{*}$ &, $051^{*}$ & $-34,7306^{*}(20 / 11 / 2008)$ \\
\hline Sabitli \& Trendli & $-49,04^{*}$ & $-49,05^{*}$ &, $05^{*}$ & $-34,9443^{*}(20 / 11 / 2008)$ \\
\hline
\end{tabular}

*, \%1 anlamlılık seviyesini ifade etmektedir. 
Hem Sabitli hem de Sabitli\&Trendli olarak tahmin edilen birim kök testleri neticesi Augmented Dickey Fuller (ADF) ve Phillips Perron (PP) test istatistiklerinin MacKinnon kritik değerlerinden mutlak değerce daha büyük oldukları kanıtlanmıştır. Seride birim kök vardır şeklinde kurulan $\mathrm{H}_{0}$ hipotezi bu sebeple reddedilmiştir. Temel hipotezi "serilerde birim kök yoktur" şeklinde kurulan Kwiatkowski-Phillips-Schmidt-Shin (KPSS) test sonuçları kritik değerlerle karşılaştıııldı̆ında, $H_{0}$ hipotezi reddedilememiş yani serilerin birim kök içermediği ayrıca kanıtlanmıştır. Veri setinin inceleme döneminde 2008 finansal krizi gibi küresel gelişmeler olduğu için getiri serilerinin yapısal kırılmalı birim kök testi olan Zivot-Andrews (ZA) birim kök testi yardımıyla da durağanlığı test edilmiştir. 2007 yılı Ağustos ayında ABD merkezli olarak ortaya çıkan ve zamanla tüm dünya sermaye piyasalarını etkisi altna Küresel Finans Krizi'nin Türkiye pay piyasasında test sonucu 20 Kasım 2008 ' de bir yapısal kırılmaya sebep olduğu, sözkonusu yapısal kırılmaya rağmen pay getiri serilerinin durağan olduğu bulunmuştur.

Hem parametrik hem de parametrik olmayan birim kök testleri ile serilerin durağanlıkları tespit edildikten sonra, getiri serilerinde değişen varyans olup olmadığının tespit edilmesi gerekmektedir. Kendi gecikmeli değerleriyle regrese edilen seride değişen varyansın varlı̆̆ı GARCH tipi volatilite modellerinin kullanılmasını gerektirecektir. Bu amaçla, AIC ve SIC değerleri dikkate alınarak en uygun ortalama denklemine ARCH-LM testi uygulanmış ve modelden elde edilen model artklarında değişen varyans sorunu ile karşılaşıldığı ve seriler normal dağılım sergilemediği için student-t dağılım için model parametreleri EO ve Bayesci yöntemlerle tahmin edilmiştir. Uygun bir GARCH modelinin ortalama ve varyans denklemindeki tüm parametrelerin istatistiki olarak anlamlı olması yanında $\alpha_{1}+\beta<1$ şartını sağlaması gerekmektedir.

\subsection{Klasik GARCH(1,1)- Student-t Modeli Sonuçları}

Student-t dağılımına göre tahmini yapılan $\operatorname{GARCH}(1,1)$ model sonuçları aşağıda sunulmuştur.

Tablo 3. BiST-100 Getiri Serisi için Student-t Dağılımlı GARCH $(1,1)$ Model Sonuçları

\begin{tabular}{|c|c|c|c|c|c|c|c|c|}
\hline \multirow{3}{*}{ BiST } & $\begin{array}{c}\text { Ortalama } \\
\text { Denklemi }\end{array}$ & \multicolumn{4}{|c|}{ Varyans Denklemi } & \multicolumn{3}{c|}{ Tanı Testleri } \\
\cline { 2 - 9 } & $r_{0}$ & $\alpha_{0}$ & $\alpha_{1}$ & $\beta$ & $v$ & $Q(10)$ & $Q^{2}(10)$ & \begin{tabular}{c} 
LM ARCH \\
test TR^2 \\
\cline { 2 - 8 } \\
$(, 000417$
\end{tabular} \\
\hline, 000118$)^{*}$ & $\begin{array}{c}, 000001146 \\
(, 000000467)^{*}\end{array}$ & $\begin{array}{c}, 06974 \\
(, 01541)^{*}\end{array}$ & $\begin{array}{c}, 9094 \\
(, 02169)^{*}\end{array}$ & $\begin{array}{c}6,093 \\
(, 7094)^{*}\end{array}$ & 12,24 & 10,36 & 12,22 \\
\hline
\end{tabular}

*Tabloda yer alan $Q$ ve $Q^{2}(10)$ gecikmede otokorelasyon Ki-Kare test istatistiklerini, $L M A R C H$ test TR^2 değişen varyans ve GARCH etkisi, Ki-Kare test olasılıklarını, parantez içindeki değerler ise standart hataları ifade etmektedir. Modelin log olabilirlik değeri 9072'dir.

Tablo 3'de sonuçları sunulan GARCH(1,1)- student-t modelinden tüm parametrelerin katsayıları pozitif olması durağanlık şart için önemlidir. Ayrıca $\left(\alpha_{1}\right)$ ARCH terimi ile $(\beta)$ GARCH teriminin toplamı ,9791 seviyesinde ve 1'den küçüktür. Student-t dağıımına göre tahmini yapılan GARCH(1,1) modeli sonuçlarına göre BiST-100 getiri serisinde şokların volatilite üzerindeki etkisi $\left(\alpha_{1}\right), 06974$ seviyesinde ve şokların volatilite üzerindeki etkisinin hangi hızda azalacağı $\left(\alpha_{1}+\beta\right) 0.9791$ seviyesindedir. Dolayısıyla tahmin edilen $\left(\alpha_{1}\right) \operatorname{ARCH}$ terimi ile ( $\beta$ ) GARCH teriminin toplamı da $1^{\prime}$ 'den küçüktür. Model artklarında otokorelasyon ve değişen varyans sorununun olup olmadığı ve $G A R C H$ etkisi $Q$ testi ve $L M A R C H$ test $T R^{\wedge} 2$ testi ile araştırılmıştır. Modelden elde edilen artiklarda otokorelasyon sorunu olmadığı ve artıkların sabit varyansa sahip olduğu Klasik GARCH(1,1)-student-t modeli sonuçlarına göre tespit edilmiştir. 
Şekil 2. Standart Artıkların QQ Grafikleri
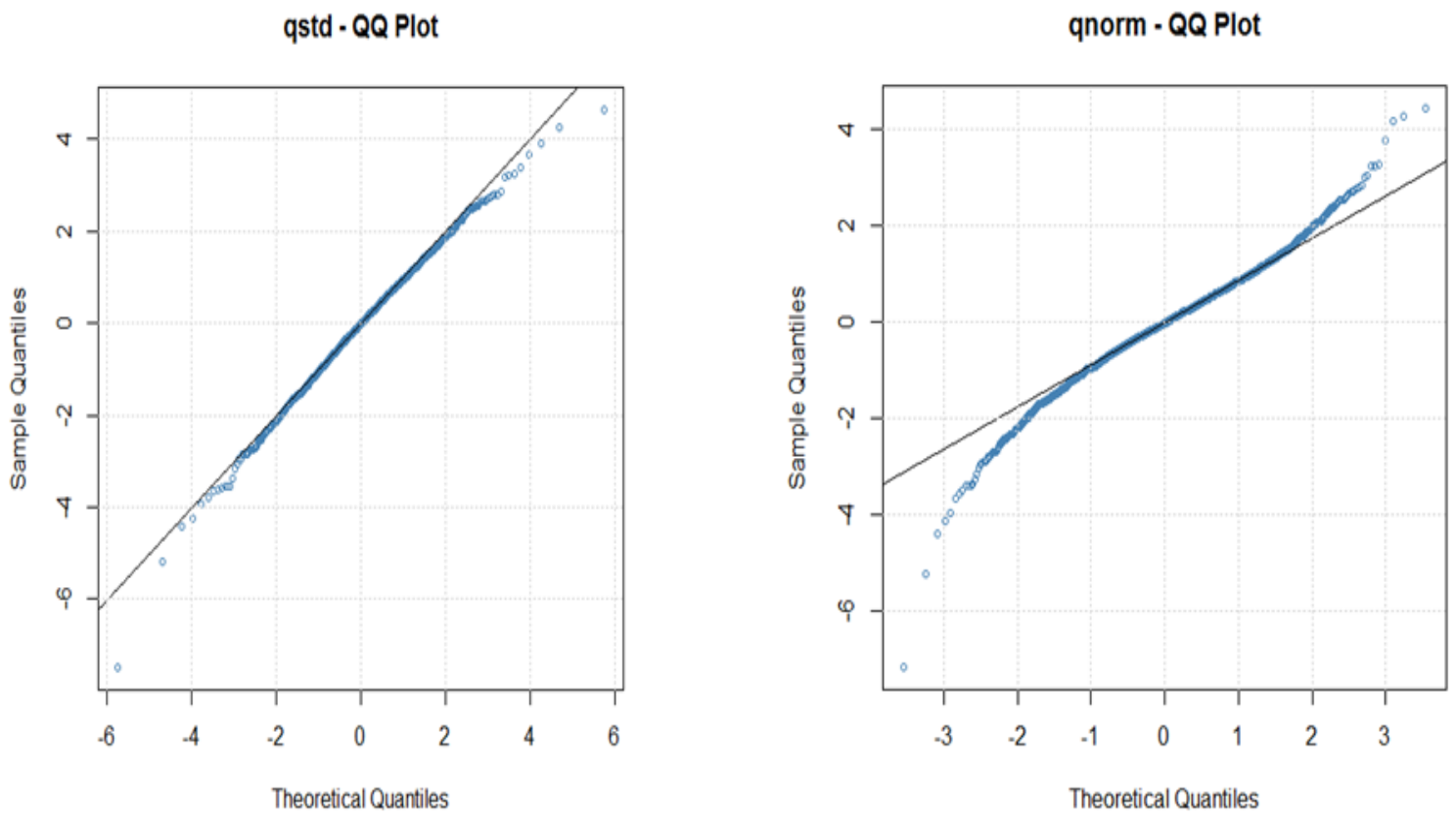

Şekil 2' de student-t dağılımıyla tahmin edilen GARCH(1,1) model artıklarının QQ grafikleri sol panelde verilmiştir. Artkkların student-t dağılımına uyduğu gözlemlenmiştir. Grafiğin sağ panelinde ise çalışma metni içerisinde yer almamasına rağmen normal dağııımla tahmin edilen $\operatorname{GARCH}(1,1)$ model artiklarının QQ grafiği verilmiştir. Burada artkkların normal dağılıma uymadığı gözlenebilmektedir. Bundan dolayı da normal dağılım varsayımı altında tahmin edilen $\mathrm{GARCH}(1,1)$ model sonuçları metin içinde sunulmamıştır.

\subsection{Bayesci GARCH $(1,1)$ Student-t Sonuçları}

BIST-100 endeksinde işlem gören pay senetlerinin getirileri Bayesci GARCH $(1,1)$-student-t modeli ile analiz edilmiştir. Artkkların Student-t dağılımına sahip olduğu $\mathrm{GARCH}(1,1)$ modelinin parametre tahminleri, $R$ programında bayesGARCH modülü kullanılarak MCMC yöntemlerinden Metropolis Hastings algoritmaları ile bulunmuştur. Model varsayımlarının sağlanması için $\lambda=0.001, \delta=2$ alınarak, modeldeki artıkların student-t dağılması sağlanmıştır. MCMC analizinde iki farklı zincirin herbiri için 100.000 iterasyon uygulanmış, model parametrelerinin yakınsamaları 80.000' inci iterasyondan sonra sağlandığı için ve bu değer yakma periyodu olarak alınmıştır. Yakma periyodundan sonraki her iki zincir için 20.000 iterasyonla sonsal özetler, standart sapma ve \%; belirtilen olasılık düzeylerinde hesaplanan kantil değerleri Tablo 4'de sunulmuştur. Buna göre BIST-100 getiri serisinde şokların volatilite üzerindeki etkisi ,093 ve şokların volatilite üzerindeki etkisinin hangi hızda azalacağı $\left(\alpha_{1}+\beta\right)$ 0,963 seviyesinde bulunmuştur. Benzer şekilde $\alpha_{1}+\beta<1$ koşulu Bayesci GARCH $(1,1)$-student-t modeli içinde sağlanmıştır. Ayrıca her iki zincir için yakınsamanın gerçekleştiğine dair parametrelerinin iz grafikleri, yakma periyodundan sonraki iterasyonlar için Şekil 2'de gösterilmiştir. Bütün grafikler incelendiğinde model parametrelerinde yakınsama sorunu olmadığı gözlenmiştir. Yakınsamanın gerçekleştiğine dair diğer bir kanıt, Brooks-Gelman-Rubin tanı testi sonuçlarının 1'e yakın çıkmasıdır. Son olarak Bayesci GARCH (1,1)-student-t model parametrelerinin sonsal olasılık yoğunluk fonksiyonları Grafik 3' de sunulmuştur. Bu sonsal olasılık yoğunluk fonksiyonları incelendiğinde $\alpha_{0}$ parametresinin sonsal dağılımı sağa çarpık, $\alpha_{1}$ parametresinin sonsal dağıımı simetrik, $\beta$ parametresinin sonsal dağııımının sola çarpık olduğu görülmektedir. 
M. B. Kilic - I. Celik - M. Kaya

Tablo 4. Bayesci GARCH(1,1)-Student -t Modeli İçin Sonsal Özetler

\begin{tabular}{|c|c|c|c|c|c|c|c|}
\hline Parametre & Ortalama & $\begin{array}{c}\text { Standart } \\
\text { Sapma }\end{array}$ & $\mathbf{\% 2 . 5}$ & $\mathbf{\% 2 5}$ & $\mathbf{\% 5 0}$ & $\mathbf{\% 7 5}$ & \%97.5 \\
\hline$\alpha_{0}$ & 0,00000228 & 0,000000608 & 0,00000129 & 0,00000185 & 0,00000221 & 0,00000264 & 0,00000367 \\
\hline$\alpha_{1}$ & 0.093 & 0.0161 & 0.065 & 0.082 & 0.092 & 0.103 & 0.128 \\
\hline$\beta$ & 0.87 & 0.023 & 0.81 & 0.85 & 0.87 & 0.88 & 0.90 \\
\hline$v$ & 6.48 & 0.85 & 5.09 & 5.90 & 6.37 & 6.96 & 8.40 \\
\hline
\end{tabular}

Şekil 3. Bayesci-GARCH(1,1)-Student-t Model Parametrelerinin İki Zincir İçin Yakınsama Grafikleri
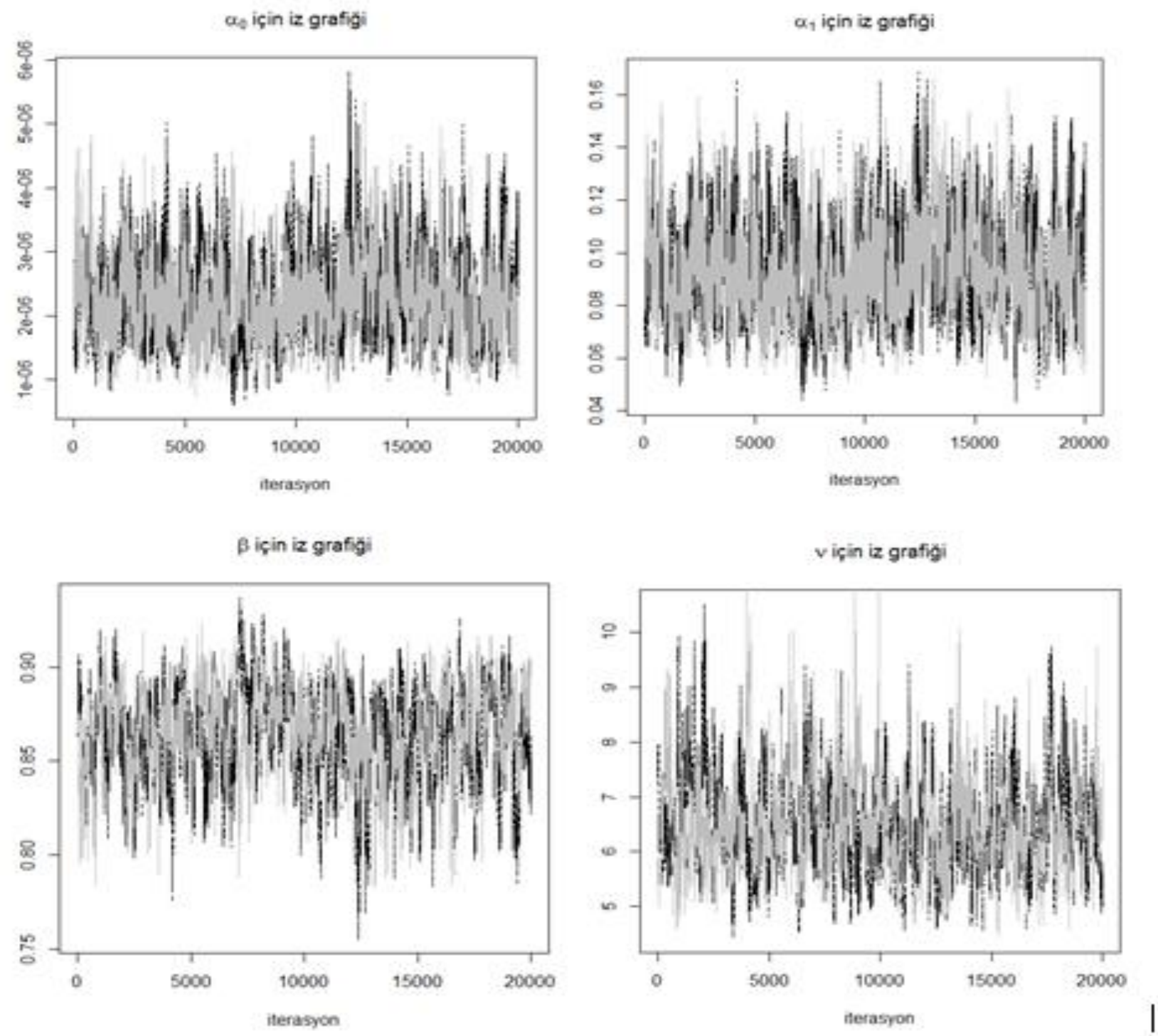
Şekil 4. Bayesci-GARCH(1,1)-Student-t Model Parametreleri İçin Sonsal Olasılık Fonksiyonları
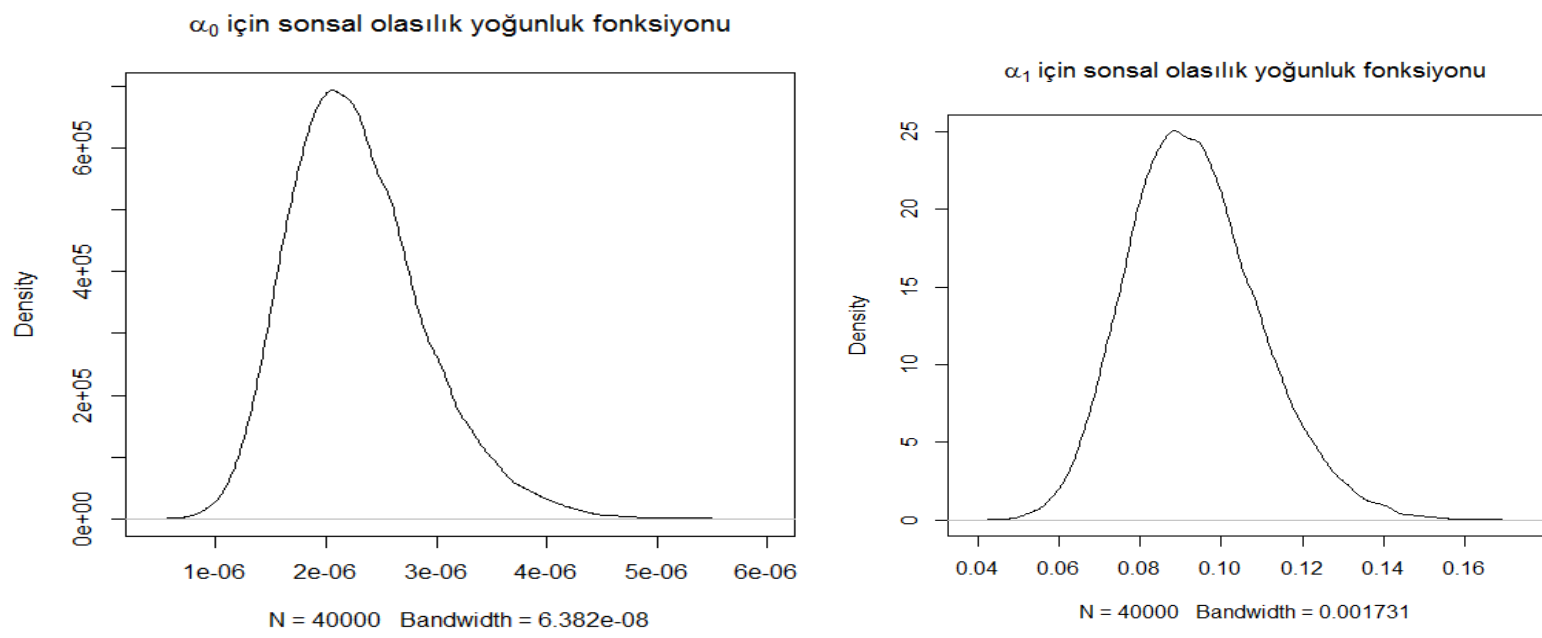

$\beta$ için sonsal olasılık yoğunluk fonksiyonu
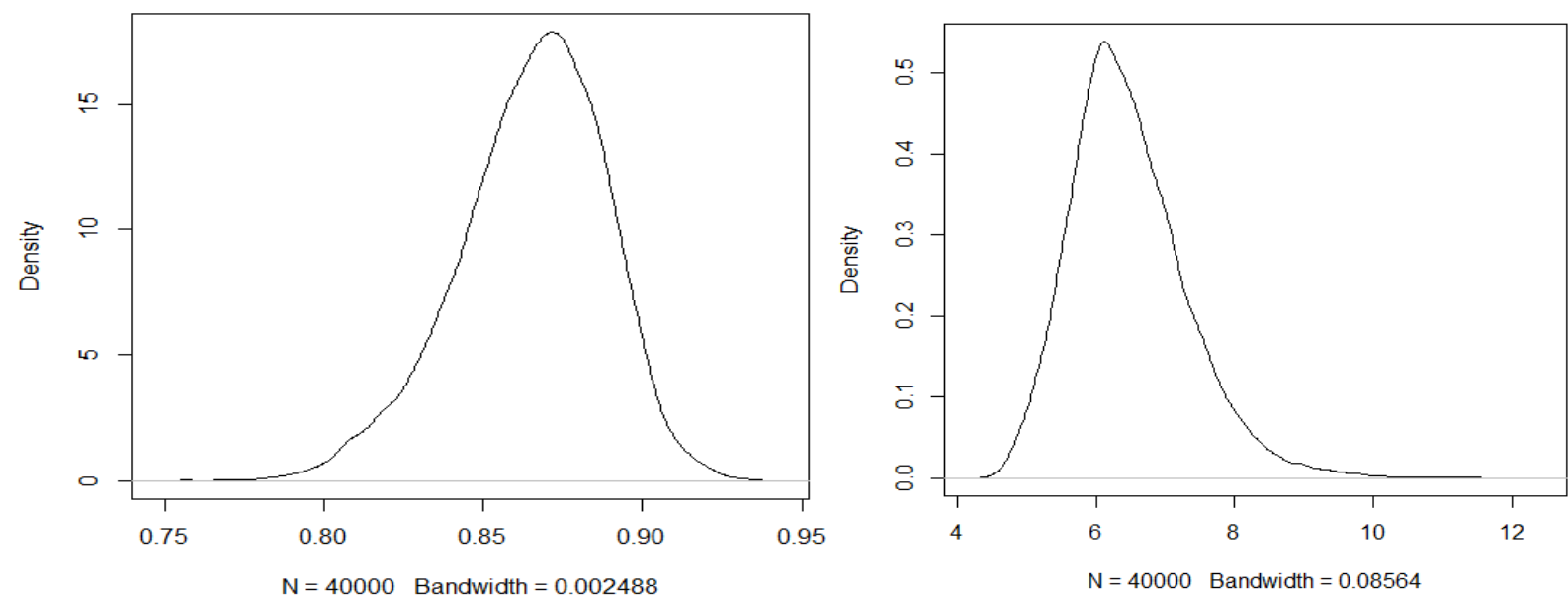

GARCH(1,1)-student-t modeli ile Klasik ve Bayeci tahmin yöntemleriyle BiST-100 verisi üzerinde incelenmiş ve benzer sonuçlar göstermiştir. Bu çalışmada $\alpha_{0}$ parametresi için EO metodundan elde edilen standart hata değeri Bayesci metottan elde edilen standart sapma değerinden daha büyük olup, diğer parametreler için EO metodundan elde edilen standart hata değerleri Bayesci metottan elde edilen standart sapma değerinden biraz daha küçük çıkmıştır.

\section{Sonuç}

Finansal sermaye akımlarının serbestçe dolaşımda olmasının bir sonucu olarak pay piyasaları arasındaki entegrasyon artmıştır. Sermaye piyasalarındaki bu gelişmeler, portföy çeşitlendirmesinde piyasaya ulaşan bilgiden kaynaklanan volatilitenin etkisinin ve kalıcılığının doğru tahmin edilmesini önemli bir konu haline getirmiştir. Son dönemlerde yurtdışı piyasalar üzerine yapılan deneysel uygulamalarda pay senedi getiri volatilitesinin tahmininde Bayesci GARCH uygulamalarının kullanıldığı görülmektedir (lqbal, 2016, Hoogerheide vd., 2012). Türkiye sermaye piyasası üzerine yapılan çalışmalarda ise Bayesci GARCH tahmin yöntemlerinin sayıca az olması bu çalışmaya ayrı bir önem katmıştır. Çalışmanın bir diğer önemi ise artıkların basık karakter özelliği göstermesinden dolayı, pay piyasalarındaki volatiliteyi normal artıklarla modellemek yerine, normal olmayan artklarla yapılan $\operatorname{GARCH}(1,1)$-student-t modelinin kullanılmasıdır. BiST-100 endeks verisi kullanılarak yapılan analiz sonuçları değerlendirildiğinde parametre tahminleri açısından $\mathrm{GARCH}(1,1)$ student-t modelinin Bayesci ve Klasik yöntemlerle arasında çok büyük farklılıklar gözlenmemiştir. Bu çalışmadan elde edilen sonuçlar, hata terimlerinin normal dağılımı varsayımı ile klasik $\operatorname{GARCH}(1,1)$, hata 
terimlerinin student-t dağıldığı Bayesci GARCH(1,1) model sonuçlarını kıyaslayan Güriş ve Saçıldı (2011)'nın çalışmasındaki Bayesci GARCH(1,1)-student-t model sonuçlarıyla benzerlik gösterdiği görülmüştür. Ancak bu çalışmanın model parametrelerinin yakınsaması için gerekli olan iterasyon sayısının daha uzun olduğu gözlenmiştir. Araştırma sonuçları aynı zamanda model karşılaştırması açısından Hoogerheide vd. (2012)'nin farklı piyasalarda ve farklı zamanlarda yaptı̆̆ çalışma sonuçlarıyla da örtüşmektedir. Son olarak, hata terimlerinin dağılımında sadece student-t dağııımı varsayımı, çalışmanın sınırları arasındadır. Sonuç olarak BIST-100 açısından her iki tahmin yöntemi, normal olmayan artklar için pay senedi getiri volatilitesinin modellenmesinde yatırımcılara ve piyasa düzenleyicilerine yatırım riskinin tahmini açısından güvenilir sonuçlar sunmaktadır.

\section{Son Notlar}

1. Klasik GARCH(1,1)-student t analizi Bollerslev (1987) tarafindan geliştirilen GARCH modeli ile yapılmıştr.

2. Bayesci GARCH(1,1)-student t analizi Geweke(1983) tarafindan geliştirilen GARCH modeli ile yapılmıştır.

3. Klasik ve Bayesci GARCH(1,1)-student-t tahminleri R programı içerisinde fGarch, bayesGARCH paketleri kullanılarak yapılmıştır.

\section{Kaynaklar}

Altuntaş, T.S., \& Çolak, D.F. (2015). BiST-100 endeksinde volatilitenin modellenmesi ve öngörülmesinde ARCH modelleri. Istanbul Üniversitesi İ̧̧letme Fakültesi İ̧̧letme iktisadı Enstitüsü Yönetim Dergisi, 26(78), 208-223.

Amiri, E. (2010). Bayesian volatility forecasting in the Tehran Stock Market. International Conference on Financial Theory and Engineering, $h$ ttp://ieeexplore.ieee.org/document/5499420/.

Ardia, D. (2008). Financial risk management with Bayesian estimation of GARCH models: Theory and applications. Volume 612 of Lecture Notes in Economics and Mathematical Systems . Springer-Verlag,Berlin, Germany, June 2008. ISBN 978-3-540-786566.URL http://www.springer.com/economics/econometrics/book/978-3-540-786566.

Ardia, D., \& Hoogerheide, L. F. (2010). Bayesian estimation of the $\operatorname{GARCH}(1,1)$ model with student- $t$ Innovations. The R Journal 2, 41-47. http://journal.rproject.org/.

Atakan, T. (2009). Istanbul Menkul Kıymetler Borsasında değişkenliğin (volatilitenin) Arch-Garch yöntemleri ile modellenmesi. istanbul Üniversitesi İsletme Fakültesi Ișletme iktisadı Enstitüsü Yönetim Dergisi, 62, 48-61

Baillie, R.T., \& Bollerslev, T. (1989). The message in daily exchange rates: A conditional-variance tale. Journal of Business and Economic Statistics, 7(3), 297-305.

Baillie, R.T., \& Bollerslev, T. (1991). Intra-day and inter-market volatility in foreign exchange rates. The Review of Economic Studies, 58(3), 565-585.

Bollerslev, T. (1986). Generalized autoregressive conditional heteroskedasticity. Journal of Econometrics, 31, 307-327.

Bollerslev, T. (1987). A Conditionally Heteroskedastic Time Series Model for Speculative Prices and Rates of Return. Review of Economics and Statistics, 69, 542-547.

Deschamps, P. J. (2006). A flexible prior distribution for Markov switching otoregressions with student-t errors. Journal of Econometrics, 133(1), 153-190.

Engle, R.F., \& Gau, Y-F. (1997). Conditional volatility of exchange rates under a target zone. University of California, San Diego, Department of Economics Discussion Paper Series 06.

Engle, R.F., Ito, T., \& Lin, W-L. (1990). Meteor showers or heat waves? Heteroskedastic intra-daily volatility in the foreign exchange market. Econometrica, 58(3), 525-542.

Eryılmaz, F. (2015). Modelling stock market volatility: The case of BIST-100. Annals of the Constantin Brâncuşi University of Târgu Jiu, Economy Series, Issue 5/2015, 37- 47.

Geweke, J. F, (1993). Bayesian treatment of the independent student-t linear model. Journal of Applied Econometrics, $8(1), 19-40$. 
Pay Piyasalarında Getiri Volatilitesinin Modellenmesi: BisT -100 İçin Klasik ve Bayesci GARCH Yaklaşımları

Gökbulut, R.i., \& Pekkaya, M. (2014). Estimating and forecasting volatility of financial markets using asymmetric GARCH models: An application on Turkish Financial Markets. International Journal of Economics and Finance, 6(4), 23 35.

Göktaş, Ö., \& Hepsağ, A. (2016). BIST-100 endeksinin volatil davranışlarının simetrik ve asimetrik stokastik volatilite modelleri ile analizi. Gazi Üniversitesi Ekonomik Yaklaşım Dergisi, 27(99), 1-15

Güriş, S, \& Saçıldı, S. i. (2011). İstanbul Menkul Kıymetler Borsası'nda pay getiri volatilitesinin klasik ve Bayesci GARCH modelleri ile analizi. Trakya Üniversitesi Sosyal Bilimler Dergisi, 13(2), 153-172.

Hastings, W. K. (1970). Monte Carlo sampling methods using Markov chains and their applications. Biometrika, 57, 97-109.

Ho, W.S., Lee, A., \& Marsden, A. (2011). Use of Bayesian estimates to determine the volatility parameter input in the Black-Scholes and binomial option pricing models. Journal of Risk and Financial Management, 3, 74-96.

Hoogerheide, L. F., Ardia, D., \& Corre, N. (2012). Density prediction of stock Index return using GARCH models: Frequentist or Bayesian estimation?. Economic Letters, 116, 322-325.

Hsieh DA. 1989a. M odeling heteroscedasticity in daily foreign-exchange rates. Journal of Business and Economic Statistics 7(3): 307-317.

Hsieh DA. 1989. Modeling Heteroscedasticity in Daily Foreign-Exchange Rates. Journal of Business and Economic Statistics ,7(3), 307-317.

lqbal F., (2016). Risk forecasting of Karachi Stock Exchange: A comparison of classical and Bayesian GARCH models. Pakistan Journal of Statistics and Operation Research, 7(3), 453-465.

Johnston, K., \& Scott, E. (2000). GARCH models and the stochastic process underlying exchange rate price changes. Journal of Financial and Strategic Decisions, 13(2), 13-24.

Karabacak, M., Meçik, O., \& Genç, E. (2014). Koşullu değişen varyans modelleri ile BisT 100 endeks getirisi ve altın getiri serisi voltilitesinin tahmini. Uluslararası Alanya İşletme Fakültesi Dergisi, 6(1), 79-90.

Karolyi, G. A. (2001). Why stock return volatility really matters. Paper Prepared for Inaugural Issue of Strategic Strategic Investor Relations, Institutional Investor Journals Series, February.

Kayahan, C., Kandemir, T., Baykut, E., \& Memiş, C. (2015). An assessment of volatility \& models: A case study for Borsa Istanbul (BIST). Archieves of Business Research, 3(2), 73-87.

Nakatsuma, T., \& Tsurumi, H. (1996). ARMA-GARCH models: Bayes estimation versus MLE, and Bayes nonstationarity test. Working Paper No. 9619. Department of Economics,

Rutgers University, New Jersey.

Metropolis, N., Rosenbluth, A. W., Rosenbluth, M. N., Teller, A. H., \& Teller, E. (1953). Equations of state calculations by fast computing machines. J. Chem. Phys. 21, 1087-92.

Yıldız, B. (2016). Oynaklık tahmininde simetrik ve asimetrik GARCH modellerinin kullanılması: Seçilmiş BiST alt sektör endeksleri üzerine bir uygulama. Muhasebe ve Finansman Dergisi, 72, 83-105. 